\title{
The Mechanism of CagA and VacA in Gastric Cancer under the Tumor Microenvironment and Vitro Factors
}

\author{
Zhu Jiang Dai ${ }^{1}$, Hui Wen Fang ${ }^{1}$, Jing Qiu Zhang ${ }^{2}$, Qi Wu ${ }^{1}$, Jia Ming Xu ${ }^{2}$, Han Jian Zhu ${ }^{2}$, Jin Gao ${ }^{2}$, \\ Zhuang Zhuang Liu ${ }^{2}$, Dong Tang ${ }^{2 \#}$, Dao Rong Wang ${ }^{2 \#}$ \\ ${ }^{1}$ Clinical Medical college, Yangzhou University, Yangzhou 225001, Jiangsu, China; ${ }^{2}$ Department of General Surgery, Institute of \\ General Surgery, Clinical Medical College, Yangzhou University, Yangzhou 225001, Jiangsu, China
}

\begin{abstract}
Gastric cancer is closely related to the stomach microbiota, especially Helicobacter pylori. Numerous reports and clinical studies have shown that microbial behavior in the stomach may lead to pathological changes in the gastrointestinal tract of the host, which ultimately leads to the production and development of gastric cancer. This review outlines the major pathogenic processes of Helicobacter pylori in the stomach, specifically focusing on CagA, VacA, inflammatory pathways and oxidative stress. In addition, we describe the effects of some non-Helicobacter pylori factors, such as other microbiota, alcohol, and tobacco, on the carcinogenesis induced by Helicobacter pylori. The effects of family history are also taken into account. We hope that understanding the stomach microbiota will make it possible to more easily prevent, detect and treat gastric cancer.
\end{abstract}

Key words: Microbiota; Gastric cancer; Helicobacter pylori; CagA; VacA; Inflammatory pathway

\section{Introduction}

Gastric cancer $(\mathrm{GC})$ is the fourth most common cancer and the second leading cause of cancer death worldwide [1]. About half of all cases and deaths due to GC occur in China, which causes a heavy burden on the Chinese healthcare system [2]. The stomach has been considered sterile, but in fact contains a variety of bacterial communities [3]. The best-known bacterium is Helicobacter pylori (H. pylori). In many areas of the world, including various parts of Asia, H. pylori infection rates are directly correlated with the rates of GC. [4]. However, while it has been known for several decades that $H$. pylori is related to GC $[5,6]$, the mechanisms by which it induces carcinogenesis, and other factors that regulate the response to $H$. pylori infection, are still being uncovered.

We herein review recent research on the stomach microbiome and the mechanisms underlying $H$. pyloriinduced carcinogenesis. These studies clearly demonstrate the pathological effects of certain microbial communities on the stomach [7]. As is well-known, H. pylori causes a variety of pathological changes in the host stomach, including chronic gastritis, atrophy, intestinal metaplasia and GC [8]. This review describes the recent findings regarding the major pathogenic processes associated

\footnotetext{
"Corresponding authors: Dao Rong Wang, MD, PhD, Department of General Surgery, Institute of General Surgery, Northern Jiangsu Province Hospital, Clinical Medical College, Yangzhou University, Yangzhou 225001, Jiangsu China; Tel: +86 1390525 2590; +86 0514 8737 3395; Email: daorong666@sina.com; Dong Tang, MD, PhD, Department of General Surgery, Institute of General Surgery, Northern Jiangsu Province Hospital, Clinical Medical College, Yangzhou University, Yangzhou 225001, Jiangsu China; Tel: +86 1895278 3556; +86051487373395; Email: 83392785@qq.com
}

with $H$. pylori in the stomach, focusing on cytotoxinassociated gene A (CagA), vacuolating cytotoxin A (VacA), inflammatory pathways and oxidative stress. We also describe the effects of some non-Helicobacter pylori factors, such as other microbes, alcohol, and tobacco, on the induction of carcinogenesis by $H$. pylori. In addition, we take into account the effects of family history, and explore the impact of the host's genetics on the $H$. pylori-mediated carcinogenesis. As more information becomes available about the stomach microbiota, we hope that it will become possible to prevent, detect and treat gastric cancer by using more advanced methods for gastric cancer screening and via microbial regulation.

\section{The Carcinogenic Effects of $\boldsymbol{H}$. pylori in the Human Stomach}

The highly acidic environment in the stomach is lethal to many species of bacteria and parasites. However, there are others that have adapted to survive under such harsh conditions, including H. pylori. H. pylori has become symbiotic with humans [9], gradually evolving the ability to settle and survive in the highly acidic stomach of the human body [10]. Examples of such adaptations by $H$. pylori include the ability to change their shape and the number of flagella to maintain motility and chemotaxis in a viscous environment $[11,12]$. The bacteria also produce urease and other factors that help them adapt to the acidic conditions in the lumen [13] and mediate the preferential colonization of H. pylori at sites of gastric injury [14].

\section{CagA}

The cag pathogenicity island is a special fragment present in a $40 \mathrm{~kb}$ DNA sequence that encodes the CagA 
protein and the type IV secretion system (T4SS) $[15,16]$. CagA is injected into the cytoplasm of gastric epithelial cells by $H$. pylori through the T4SS structure [17]. It has been demonstrated that CagA is a key factor involved in human chronic gastritis and ulcers, mucosa-associated lymphoid tissue lymphoma and GC [18]. Additionally, studies have shown that CagA-positive strains of bacteria are associated with a several-fold increase in the risk of GC compared with CagA-negative strains [19]. A meta-analysis further confirmed that individuals infected with CagA-positive H. pylori strains had an increased risk of developing GC [20,21].

CagA is a macromolecular cytoplasmic protein produced. Due to the structural differences in the C-terminal region, the molecule is subject to change [22], ranging from between about 120 and $140 \mathrm{kD}$ in length. CagA has a tyrosine phosphorylated region and a non-phosphorylated region [23]. Interestingly, the Glu-Pro-Ile-Tyr-Ala (EPIYA) motif present in the $\mathrm{C}$-terminal region is a target for phosphorylation by Src family kinase (SFK) [24] and Abl families [25], while other regions are unable to undergo phosphorylation. CagA binds to various signaling proteins and causes dysregulation of multiple signaling pathways in a phosphorylation-dependent or -independent manner, inducing cancer via these pathways [26].

\section{Tyrosine Phosphorylation}

After tyrosine phosphorylation, segments $\mathrm{C}$ and D of EPIYA (EPIYA has four segments A, B, C, and D [27]) acquire the ability to bind to the Src-homology-2 domain containing PTPase (SHP2) [28] (Figure 1). SHP2 is a tyrosine phosphorylase that plays an important role in cell mitosis [29]. Although it has been suggested that East Asian CagA and Western CagA use different mechanisms to deregulate SHP2 [30], CagA binds to SHP2, activates SHP2 activity [28], enhances Ras-extracellular regulated protein kinases (Erk) signaling [31], and promotes abnormal mitosis. Studies have also shown that SHP2 is a protooncogene phosphatase [32], suggesting a link between CagA and GC. Researchers have shown that CagA interacts with $\mathrm{C} 10$ regulator of kinase (Crk) to play an important role in the reduction of gastric epithelial cell adhesion caused by H. pylori [33]. Crk-induced Src activation and the subsequent signaling of p38 mitogen-activated protein kinase (MAPK) promote the proliferation of sarcoma cells [34]. There is also an interaction between phosphorylated CagA and CagA-c-terminal Src kinase (Csk) [35] that leads to cell elongation called the "hummingbird phenotype" [36]. Csk phosphorylation inhibits SFK kinase activity, resulting in decreased EPIYA phosphorylation of CagA, which can effectively prevent tyrosine phosphorylation-dependent

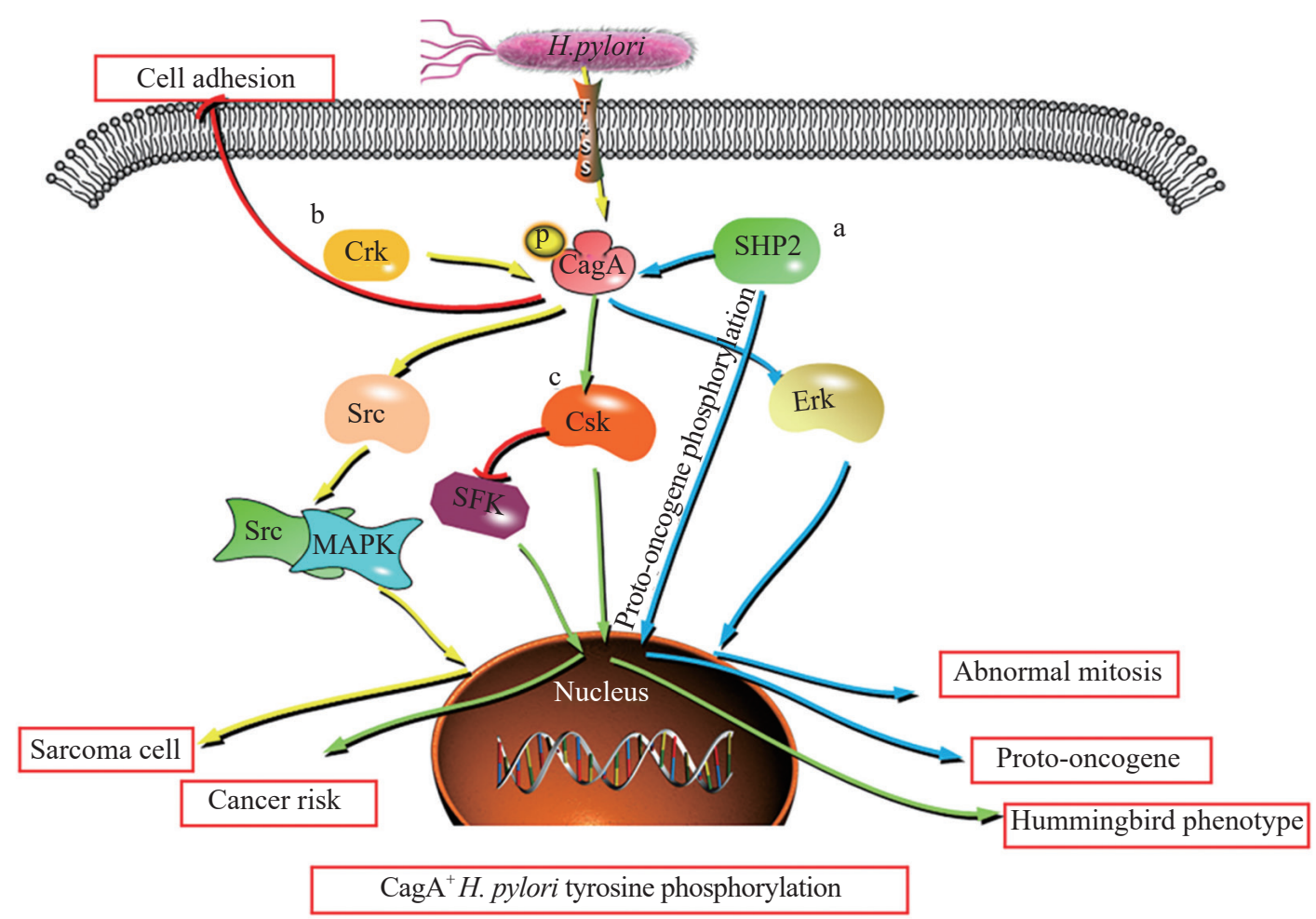

Figure 1 The CagA-positive $\boldsymbol{H}$. pylori tyrosine phosphorylation pathway. (a) SHP2 acts as a tyrosine phosphorylase and proto-oncogene phosphorylase. It binds to CagA, enhances Erk signaling, and promotes abnormal mitosis. (b) CagA interacts with Crk to reduce the adhesion of gastric epithelial cells. Crk can induce the Src and MAPK pathways, promoting the proliferation of sarcoma cells. (c) Phosphorylated CagA can also interact with Csk to induce a "hummingbird phenotype" in cells. At the same time, Csk's inhibition of SFK is weakened, which will increase the risk of cancer. 
overactivation of CagA activity. Although this has been suggested to have inhibitory effects on $H$. pylori [37], the bacterium remains closely associated with the development of GC.

\section{Non-Tyrosine Phosphorylation}

In the absence of tyrosine phosphorylation, there is dysregulation of various signaling pathways. In the phosphorylation-independent pathway, unphosphorylated CagA interacts with various signaling proteins, such as hepatocyte growth factor receptor (c-met), E-cadherin [38], growth factor receptor-bound 2 (Grb2) [39], and partitioning-defective $1 \mathrm{~b}$ (Parlb) [40], and then activates the corresponding signaling pathway (Figure 2). H. pylori CagA targets the c-met receptor and enhances the cell motility. During the translocation process, CagA regulates cellular function by releasing the c-met receptor signal [41].

The occurrence of GC is inseparable from the process of inflammation. The CagA protein negatively regulates autophagy and promotes an inflammatory response to $H$. pylori infection. This inflammatory response is regulated by activation of the c-met-phosphoinositide 3-kinase (PI3K)/ protein kinase $\mathrm{B}$ (Akt)-mammalian target of rapamycin (mTOR) signaling pathway [38]. The PI3K/Akt signaling pathway is strongly activated in GC [42].

H. pylori CagA also interacts with E-cadherin to promote beta-catenin signaling and the intestinal metaplasia of gastric epithelial cells [43], a precancerous lesion of the stomach. CagA interacts with Grb2, which activates the Ras/MEK/ERK pathway, leading to cell proliferation [39]. The interaction between CagA and Parlb inhibits Parlb kinase activity, affects the actin cytoskeletal system, and

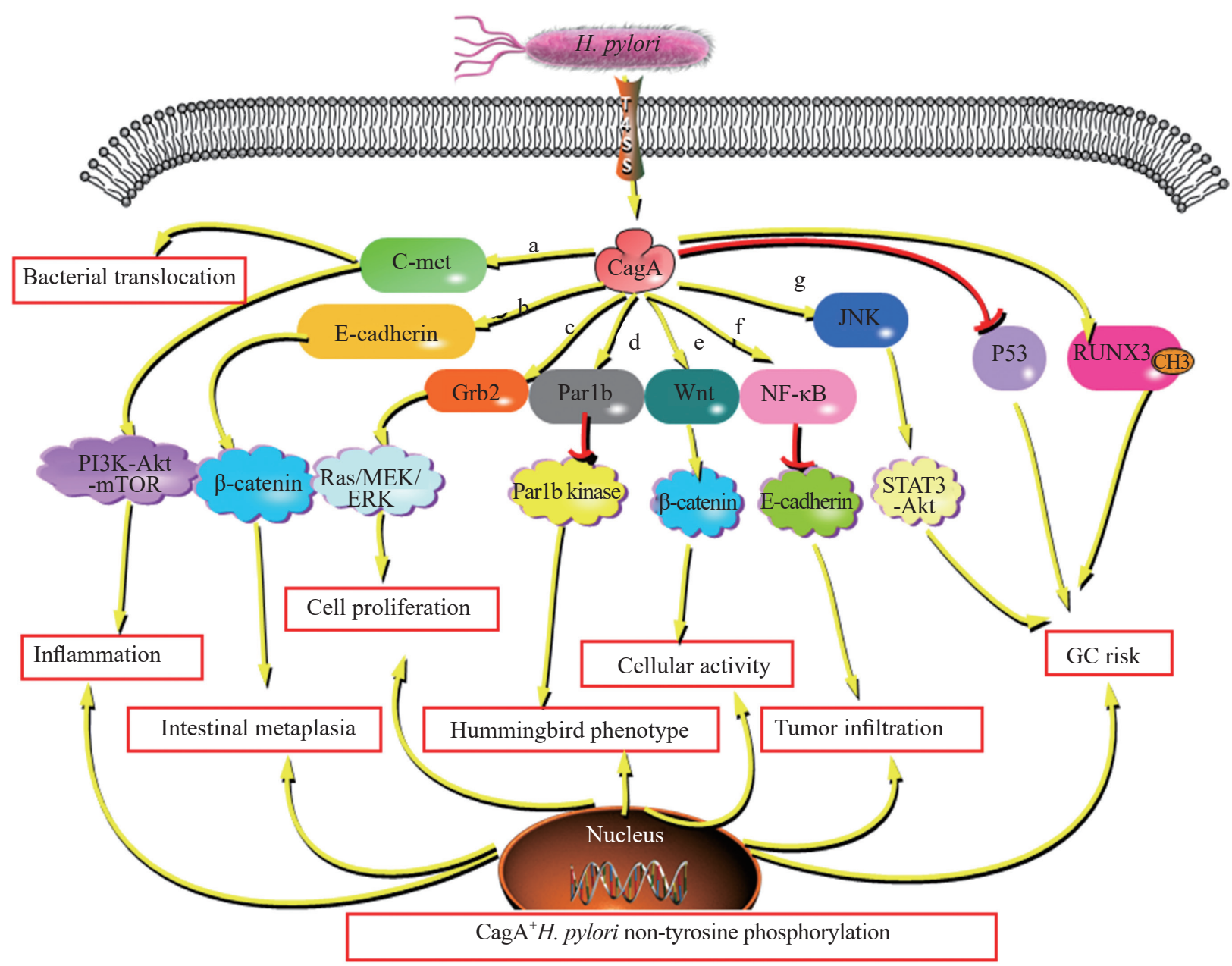

Figure 2 The CagA-positive H. pylori non-tyrosine phosphorylation pathway. (a) CagA binds to c-met, releasing receptor signals to promote bacterial translocation. At the same time, the c-met pathway activates the downstream PI3K-Akt-mTOR pathway and participates in the inflammatory response. (b) CagA interacts with E-cadherin to induce $\beta$-catenin signaling and promote the intestinal metaplasia of gastric epithelial cells. (c) CagA interacts with Grb2 to activate Ras/MEK/ERK, resulting in cell proliferation. (d) The actions of CagA and Parlb inhibit Parlb kinase activity and enhances the "hummingbird phenotype". (e) CagA activates the highly conserved Wnt/ $\beta$-catenin pathway and promotes gastric cancer stem cell activity. (f) CagA induces NF- $\kappa \mathrm{B}$, decreases the expression of E-cadherin, and participates in tumor invasion. (g) CagA induces the JNK pathway and activates the STAT3-Akt signaling axis. At the same time, CagA inhibits p53 and induces RUNX3 methylation, leading to an increased risk of gastric cancer. In each of these processes, the nucleus is involved in the regulation of cellular activities. 
enhances the size of cells with the hummingbird phenotype [40]. Neal JT et al. established a transgenic zebrafish model to study CagA, and found that it increases intestinal cell proliferation through activation of the Wnt pathway, leading to $\mathrm{GC}$ [44]. In general, the Wnt/ $\beta$-catenin signaling pathway is highly conserved among species. Thus, $H$. pylori CagApositive strains can promote the activity of human GC stem cells through the Wnt/ $\beta$-catenin signaling pathway $[45,46]$.

Kim SY et al. used eukaryotic expression vectors and showed that CagA induced NF-kappaB (NF- $\mathrm{kB}$ ) activation and IL-8 release [47]. The NF- $\mathrm{KB}$ pathway is involved in tumor invasion and metastasis by reducing the expression of E-cadherin [48]. Recently, Wandler AM et al. used the JNK (c-Jun NH2-terminal kinase) pathway activation in a Drosophila model to demonstrate that CagA acts as an important mediator of activation of this signaling pathway $[49,50]$, which ultimately promotes apoptosis or tumorigenesis. Further studies have found that there may be a carcinogenic pathway linking the JNK-STAT3-Akt signaling axis [51]. H. pylori CagA was shown to promote the development of GC through activation of gastric STAT3 [52].

Interestingly, CagA can also interfere with certain tumor suppressors [53]. The experimental results described by Wei $\mathrm{J}$ et al. provided new evidence that the tumorigenicity associated with $H$. pylori infection is associated with CagAmediated inhibition of p53 protein [54]. CagA enhances the degradation of p53 and down-regulates its activity [55]. Another study found that RUNX3 methylation was increased in poorly differentiated adenocarcinoma [56], thus decreasing the transcriptional activation of RUNX3 [57], thereby increasing the risk of GC. CagA has been drawing increasing attention in recent years, so it is possible that additional CagA-related effects will be discovered in the near future.

\section{VacA}

VacA is a vacuolar cytotoxin isolated from the supernatant of $H$. pylori culture medium, and is also a secreted toxin. VacA toxin is an $88 \mathrm{kDa}$ pathogenic factor that consists of two domains; $\mathrm{p} 33$ and p55 [58]. Torres VJ et al. demonstrated that these two domains can interact to form a protein complex, and the binding of the mixture to the plasma membrane of mammalian cells is significantly enhanced compared to the binding of the VacA domain alone $[59,60]$. After entering eukaryotic cells, VacA leads to cell vacuolization [61]. H. pylori VacA forms an anionselective channel in the planar lipid bilayer, which may induce a permeability imbalance in the intracellular acidic compartment [62]. Czajkowsky DM et al. found that when the $\mathrm{pH}$ is below 5, VacA combines with the anionic lipid bilayer to form a hexa-membrane-related complex, thereby forming pores [63]. This low $\mathrm{pH}$-triggered pore formation may be a critical step in VacA activity [64], and the acidic environment of the stomach is conducive to this activity.
VacA has a variety of effects on cells, although the most important are altering the permeability of the plasma membrane and causing vacuolation of epithelial cells $[65,66]$. VacA induces autophagy, but the mechanism underlying this finding remains unclear [67]. Raju D et al. added VacA components to cultured gastric epithelial cells, and found that VacA could induce autophagy and regulate the degradation and circulation of cellular components in the cytoplasm [68]. VacA is also involved in biological reactions in the mitochondria. Jain $\mathrm{P}$ et al. found that $H$. pylori interfered with the morphological dynamics of mitochondria [69]. Chatre L et al. also suggested that H. pylori induces mitochondrial replication [70]. These changes are consistent with the progression of gastric lesions.

VacA also has immunomodulatory and inhibitory activities on various cells of the mammalian immune system, ensuring the persistence of the host $H$. pylori [71]. VacA can inhibit the activation and proliferation of $\mathrm{T}$ cells and $\mathrm{B}$ cells, and can interfere with the antigen expression of $B$ cells [72]. It also prevents the normal maturation, antigen processing and expression of phagocytic cells, and interferes with intracellular killing and cytokine production [73]. The immune system is thus inhibited, ensuring continued infection with $H$. pylori.

VacA is similar to CagA with regard to its effects on gastric acid. Wang $\mathrm{F}$ et al. used freshly isolated rabbit gastric glands and cultured parietal cells to study the effects of VacA infection on the physiological function of parietal cells, and found that VacA penetrated into the apical membrane of these cells and induced hypochlorite production [74]. These effects echoed the earlier findings by Kobayashi's team showing that VacA affected gastric acid secretion in guinea pig isolated wall cells [75]. Animal models have also revealed that VacA plays a role in promoting gastric pathology [76,77]. For example, VacA can cause damage to the gastric mucosa, increase inflammatory cells, and induce cancer [78].

The potential interaction of CagA and VacA is not well understood. However, VacA stimulates CagA degradation through an autophagy pathway, thereby reducing the half-life of CagA [79,80]. However, in gastric cells expressing CD44v9, autophagy is prevented, allowing the accumulation of CagA [81]. Therefore, the probability of cancer increases in cells that are invaded by $\mathrm{H}$. pylori. In addition to CagA and VacA, genes such as iceA and babA2 also play a role in $\mathrm{GC}[82,83]$, mainly due to the increased risk of $H$. pylori-related diseases [84]. Moreover, there is a geographical dependence in terms of the roles and importance of the different gene products, providing some clues to the pathogenesis of $H$. pylori, and these agents are often closely related to the clinical outcomes [85].

\section{Inflammatory Response and Oxidative Stress Process}

The human immune system has innate and adaptive 
immune responses to H. pylori [86], which can chronically proliferate and actively adapt to unfavorable parts of the stomach, making it is difficult to eradicate [87]. Therefore, infection with $H$. pylori often leads to chronic inflammation, and oxidative stress may be caused by the inflammation. Although infected patients may remain asymptomatic indefinitely, $\mathrm{H}$. pylori can induce an inflammatory response in gastric epithelial cells and may lead to the circulation of immune cells through various routes. Activation of NF$\kappa \mathrm{B}$ and up-regulation of IL-8 in gastric epithelial cells are considered to be critical for both $H$. pylori-induced chronic inflammation and GC $[88,89]$. Like the microbes associated with colorectal cancer-induced inflammation, H. pylori activates NF- $\mathrm{KB}$ by binding to the toll-like receptors (TLR) of epithelial cells and binding to myeloid differentiation factor 88 (MyD88) [90] (Figure 3). Lamb A et al. demonstrated that CagA and transforming growth factor- $\beta$-activated kinase 1 (TAK1) are essential for $H$. pylori to induce NF- $\mathrm{KB}$ activation [91]. CagA induction is mediated by tumor necrosis factor receptor-associated

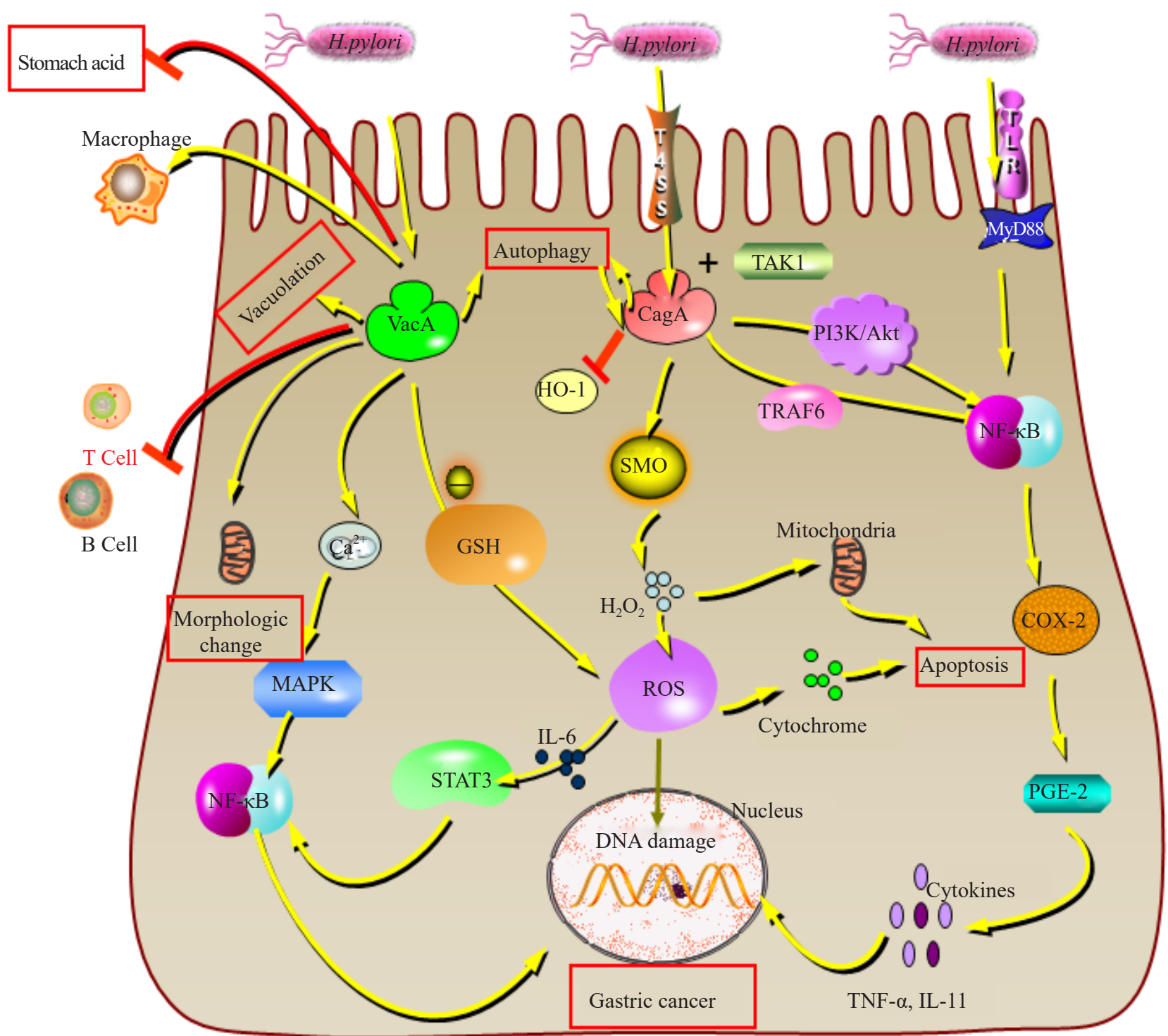

Figure 3 This image shows the carcinogenic process associated with $\boldsymbol{H}$. pylori-related inflammation and oxidative stress. In the inflammatory response, $H$. pylori binds to MyD88 via TLRs and activates NF- $\kappa B$. NF- $\kappa$ B activation activates the COX-2 and PGE2 pathways and induces the release of cytokines such as TNF- $\alpha$ and IL-11, leading to gastric cancer. H. pylori releases CagA through T4SS. CagA stimulation leads to an increase in the SMO levels in the gastric epithelium and produces $\mathrm{H} 2 \mathrm{O} 2$, leading to oxidative stress. H2O2 depolarizes the mitochondria and induces ROS production. The accumulation of ROS also depends on the toxin inhibiting the GSH pathway. ROS not only cause nuclear DNA damage, but also induce the up-regulation of IL-6, activate STAT3$\mathrm{NF}-\mathrm{kB}$, thus promoting the activation of proto-oncogenes. ROS can cause apoptosis through cytochromes. CagA also binds to TAK1 and induces NF- $\mathrm{BB}$ activation mediated by TRAF6. CagA-dependent NF- $\mathrm{BB}$ activation can also be mediated through the PI3K/Akt signaling pathway. CagA negatively regulated autophagy and inhibits the anti-inflammatory effects of HO-1, leading to inflammation. VacA activates MAPK and NF- $\mathrm{kB}$ by releasing calcium ions. VacA also causes morphological changes in mitochondria, inhibiting gastric acid secretion and immune cell function. H. pylori can lead to the development of gastric cancer through all of these pathways. 
factor 6 (TRAF6), which binds to TAK1 to induce NF$\kappa \mathrm{B}$ activation. CagA-dependent $\mathrm{NF}-\kappa \mathrm{B}$ activation can also be mediated through the PI3K/Akt signaling pathway [92]. The development of $\mathrm{GC}$ is considered to involve the combination of inflammation and oncogenes. Most tumors can induce cyclo-oxygenase (COX-2) expression, and NF$\kappa \mathrm{B}$ activation further increases the activity of the COX-2 and prostaglandin E2 (PGE-2) pathways. PGE-2 binds to the EP4 receptor [93], activates MAPK signaling [94], and induces the release of cytokines such as IL-11 and TNF- $\alpha$. COX-2 also regulates E-cadherin expression via the NF$\kappa \mathrm{B}$ signaling pathway [48], which plays a role in the CagA oncogenic pathway.

In addition to the inflammatory response, the oxidative stress induced by $H$. pylori cannot be ignored. Chaturvedi R et al. recently reported that $H$. pylori expressing CagA leads to elevated levels of spermine oxidase (SMO) in gastric epithelial cells [95]. SMO decomposes polyamine spermine, which produces hydrogen peroxide $\left(\mathrm{H}_{2} \mathrm{O}_{2}\right)$, leading to apoptosis and DNA damage. H. pylori CagA also oxidizes DNA by inducing SMO. These subpopulations of cells are often resistant to apoptosis, and therefore have a high risk of malignant transformation [96]. Hydrogen peroxide can depolarize mitochondria [97] and induce reactive oxygen species (ROS), which will continue to react with the nucleus [98]. ROS not only cause DNA damage, but also induce the upregulation of IL-6, which mediates STAT3 activation [99]. The STAT3 and NF- $\kappa$ B pathways are inextricably linked to the activation of proto-oncogenes, providing a potential link between inflammation and GC [100]. Hrycay EG et al. also found that ROS have effects on cytochromes in gastric epithelial cells and can induce apoptosis[101]. Heme oxygenase-1 (HO-1) has antioxidant and anti-inflammatory effects [102].

Interestingly, $H$. pylori CagA has been suggested to reduce the incidence of $\mathrm{GC}$ by destroying nitric oxide, reducing $\mathrm{NF}-\kappa \mathrm{B}$ activation, inhibiting heme oxygenase-1, and enhancing the inflammatory response [103]. CagA negatively regulates autophagy and promotes inflammation [104]. VacA activates p38 MAPK by inducing the release of intracellular calcium ions, directly increasing the production of IL-8, thereby activating NF- $\mathrm{B}$ [105]. VacA is a chloride channel that targets mitochondria [106]. Recent studies have provided new perspectives regarding VacAinduced loss of the mitochondrial membrane potential, mitochondrial fragmentation, reactive oxygen species formation, autophagy [107], and the mechanism underlying the development of GC. Interestingly, after further studies, Tsugawa $\mathrm{H}$ et al. found that CagA accumulation in gastric cells expressing CD44 is due to VacA causing ROS accumulation and Akt activation by decreasing the intracellular glutathione (GSH) levels [80]. CD44 is a cell surface marker associated with cancer stem cells [108]. Together, these findings provide a possible molecular link between $H$. pylori and gastric carcinogenesis.

\section{Carcinogenesis Related to Non- $H$. pylori Factors in the Human Stomach}

Although $H$. pylori infection is considered to be a major risk factor for $\mathrm{GC}$, approximately half of patients with gastritis are negative for $H$. pylori infection, and the abundance of $H$. pylori is decreasing in cancer patients. Lofgren JL et al. used a transgenic insulin-gastrin mouse model to confirm the association of gastric microbiota with the development of GC [109]. Sohn SH et al. used pyrosequencing to analyze the corpuscular microbiota and studied the possible roles of microbiota other than $H$. pylori in the development of GC [110]. Most studies on gastric microbes have shown that the most common non- $H$. pylori populations are thick-walled bacteria, Bacteroides, and Fusobacterium [111]. Hsieh YY et al. found that the number of Clostridium in gastric cancer patients in Taiwan is significantly higher than that in other gastrointestinal diseases [112]. Moreover, recent research indicated that the average age of patients with GC has been decreasing [113], which may be related to disorders of microbial metabolism in the stomach. These results also suggest that $H$. pylori is the primary microbe related to $\mathrm{GC}$, while a variety of other microbes play secondary roles $[114,115]$. In addition to the above microbial factors, alcohol and tobacco intake are also related to the incidence of GC [116]. Although various experiments are currently underway to investigate whether the interaction of alcohol with $H$. pylori can trigger GC [117], these studies are complex, and so far, the relationship between $H$. pylori and alcohol does not appear to be significant. The high incidence of CagA-positive $H$. pylori infection and precancerous lesions may also be related to the use of tobacco. Smoking can cause stomach damage, impair the healing of peptic ulcers, increase $H$. pylori infection, and increase the recurrence rate of peptic ulcers [118]. Therefore, tobacco increases the incidence of GC. Although other microbiota and alcohol may not necessarily directly affect the occurrence of GC, they may amplify the effects of $H$. pylori, accelerating the development of GC. This is an exciting area, and will also be the direction of our next phase of research on GC.

\section{H. pylori Induce Gastric Cancer in Patients with a Family History of GC}

Nishizawa $\mathrm{T}$ et al. performed single-factor and multivariate regression analyses that included the age, gender, body mass index, previous cancer history, family history of primary gastric cancer, and history of gastric ulcers in 206 patients with H. pylori infection. They concluded that family history is an independent risk factor for GC progression in patients with $H$. pylori infection [119]. At the same time, Sepulveda et al. found that patients with total gastritis with a family history of GC had higher lymphoid follicle density associated with $H$. pylori infection [120]. These two studies suggest that the interaction of $H$. pylori infection with a family history of GC increases the 
incidence of GC in these individuals. This may be used as a theoretical basis for strategies to prevent GC. Because a family history of GC is associated with an increased risk of $\mathrm{GC}$, the histological findings of gastritis may be suitable for the screening and monitoring of GC, especially in relatively young and at-risk populations. Infection with CagA-positive strains and records of family history may be useful markers for identifying patients at high risk for disease, as well as for prevention and early detection of GC.

\section{Outlook}

Microbiota is essential in the process of GC. Therefore, some measures against microbes (or that regulate specific populations of microbes) in the stomach may effectively reduce the incidence of GC. Leung WK et al. linked the treatment of $H$. pylori infection with lower risk of GC by analyzing data from Hong Kong public hospital databases [121]. Some laboratories attempted to inhibit IL-8 levels in the serum in a mouse model, and found that the $\mathrm{pH}$ of the stomach returned to normal levels, effectively inhibiting the viability of $H$. pylori [122]. Interestingly, some scholars have studied the anti-H. pylori effects of lactic acid bacteria (LAB). The concentration and morphology of organic acids were found to affect $H$. pylori infection [123]. In this way, doctors may be able to inhibit $H$. pylori activity by the delivery of new microbial populations. In addition, iron deficiency anemia [124] and high-salt [125] diets are factors that induce an increase in the invasiveness of $\mathrm{H}$. pylori, so dietary interventions may be useful. However, the specific eradication of $H$. pylori seems to be the most promising approach to prevent GC. Human studies have confirmed that the eradication of $H$. pylori can reduce the risk of $\mathrm{GC}$, a strategy that is more useful for patients without atrophic gastritis or intestinal metaplasia [126]. Of note, the presence of CagA-positive strains and a family history of GC provide useful markers for identifying patients at high risk for disease, which adds some accuracy to screening for gastric cancer. We anticipate that the technology used to both identify and eradicate $H$. pylori will be more targeted in the future, and the prevention and cure rates for $\mathrm{GC}$ will increase as a result of these and other interventions targeting the microbiome.

\section{Abbreviations}

Akt, protein kinase B;

C-Jun NH2-terminal kinase, JNK;

C-terminal src kinase, Csk;

Cyclo-oxygenase, COX-2;

Cytotoxin-associated gene A, CagA;

$\mathrm{C} 10$ regulator of kinase, $\mathrm{Crk}$;

Extracellular regulated protein kinases, Erk;

Gastric cancer, GC;

Glu-Pro-Ile-Tyr-Ala, EPIYA;

Glutathione, GSH;

Growth factor receptor-bound 2, Grb2;
Helicobacter pylori, H. Pylori;

Heme oxygenase-1, HO-1;

Hepatocyte growth factor receptor, c-met;

Hydrogen peroxide, $\mathrm{H} 2 \mathrm{O}$;

Lactic acid bacteria, LAB;

Mitogen-activated protein kinase, MAPK;

Mammalian target of rapamycin, m-TOR;

Myeloid differentiation factor 88 , myd88;

NF-kappab, NF-kB;

Partitioning-defective 1b, Parlb;

Phosphoinositide 3-kinase, PI3K;

Prostaglandin E2, PGE-2;

Reactive oxygen species, ROS;

Spermine oxidase, $\mathrm{SMO}$;

Src family kinase, SFK;

Src-homology-2 domain containing ptpase, SHP2;

Toll-like receptor, TLR;

Transforming growth factor- $\beta$-activated kinase 1, TAK1;

Tumor necrosis factor receptor-associated factor 6 , TRAF6;

Type IV secretion system, T4SS;

Vacuolating cytotoxin A, vacA

\section{Conflicting Interests}

The authors declare that there is no conflict of interests.

\section{Funding}

This research was funded by the Yangzhou Science and Technology Bureau Social Development Project of Jiangsu Province [No. YZ2018087], the training project of Key Talents of Youth Medicine in Jiangsu Province, China [QNRC2016330], the Key Disease Standardization Diagnosis and Treatment Project in Jiangsu Province [BE2015664] and the Academic Science and Technology Innovation Fund for College Students [x20180714].

\section{References}

1. Siegel RL, Miller KD, Jemal A. Cancer Statistics, 2017. CA Cancer J Clin 2017;67(1):7-30.

2. Nie Y, Wu K, Yu J, Liang Q, Cai X, Shang Y, Zhou J, Pan K, Sun L, Fang J, Yuan Y, You W, Fan D. A global burden of gastric cancer: the major impact of China. Expert Rev Gastroenterol Hepatol 2017;11(7): 651-61.

3. Shah MA. Gastric cancer: The gastric microbiota - bacterial diversity and implications. Nat Rev Gastro Hepat 2017;14(12):692-3.

4. Fock KM. Review article: the epidemiology and prevention of gastric cancer. Aliment Pharm Therap 2014;40(3):250-60.

5. Hirayama F, Takagi S, Kusuhara H, Iwao E, Yokoyama Y, Ikeda Y. Induction of gastric ulcer and intestinal metaplasia in mongolian gerbils infected with Helicobacter pylori. J Gastroenterol 1996;31(5):755-7.

6. Hirayama F, Takagi S, Yokoyama Y, Iwao E, Ikeda Y. Establishment of gastric Helicobacter pylori infection in Mongolian gerbils. J Gastroenterol 1996;31 Suppl 9: 24-28.

7. Wang LL, Yu XJ, Zhan SH, Jia SJ, Tian ZB, Dong QJ. Participation 
of microbiota in the development of gastric cancer. World J Gastroentero 2014;20(17):4948-52.

8. Gao JJ, Zhang Y, Gerhard M, Mejias-Luque R, Zhang L, Vieth M, Ma JL, Bajbouj M, Suchanek S, Liu WD, Ulm K, Quante M, Li ZX, Zhou T, Schmid R, Classen M, Li WQ, You WC, Pan KF. Association between gut microbiota and Helicobacter pylori-related gastric lesions in a high-risk population of gastric cancer. Front Cell Infect Microbiol 2018;8:202. doi: 10.3389/fcimb.

9. Cheung DY, Kim TH. Helicobacter pylori in human stomach: can it be called mutualism or a disease?. Korean J Gastroenterol 2012;59(5):329-37.

10. Ahmed N, Tenguria S, Nandanwar N. Helicobacter pylori--a seasoned pathogen by any other name. Gut Pathog 2009;1:24. doi: 10.1186/1757-4749-1-24

11. Martinez LE, Hardcastle JM, Wang J, Pincus Z, Tsang J, Hoover TR, Bansil R, Salama NR. Helicobacter pylori strains vary cell shape and flagellum number to maintain robust motility in viscous environments. Mol Microbiol 2016;99(1):88-110.

12. Qin Z, Lin WT, Zhu S, Franco AT, Liu J. Imaging the motility and chemotaxis machineries in Helicobacter pylori by cryo-electron tomography. J Bacteriol 2017;199(3):e00695-16.

13. Kuwahara H, Miyamoto Y, Akaike T, Kubota T, Sawa T, Okamoto $\mathrm{S}$, Maeda H. Helicobacter pylori urease suppresses bactericidal activity of peroxynitrite via carbon dioxide production. Infect Immun 2000;68(8):4378-83.

14. Aihara E, Closson C, Matthis AL, Schumacher MA, Engevik AC, Zavros Y, Ottemann KM, Montrose MH. Motility and chemotaxis mediate the preferential colonization of gastric injury sites by Helicobacter pylori. PLoS pathogens 2014;10(7): e1004275.

15. Khatoon J, Prasad KN, Prakash Rai R, Ghoshal UC, Krishnani N. Association of heterogenicity of Helicobacter pylori cag pathogenicity island with peptic ulcer diseases and gastric cancer. Br J Biomed Sci 2017;74(3):121-6

16. Backert S, Schwarz T, Miehlke S, Kirsch C, Sommer C, Kwok T, Gerhard M, Goebel UB, Lehn N, Koenig W, Meyer TF. Functional analysis of the cag pathogenicity island in Helicobacter pylori isolates from patients with gastritis, peptic ulcer, and gastric cancer. Infect Immun 2004;72(2):1043-56.

17. Tohidpour A, Gorrell RJ, Roujeinikova A, Kwok T. The middle fragment of Helicobacter pylori CagA induces actin rearrangement and triggers its own uptake into gastric epithelial cells. Toxins (Basel) 2017;9(8). doi: 10.3390/toxins 8060187.

18. Martínez-Carrillo DN, Atrisco-Morales J, Hernández-Pando R, Reyes-Navarrete S, Betancourt-Linares R, Cruz-del Carmen I, Illades Aguiar B, Román-Román A, Fernández-Tilapa G. Helicobacter pylori vacA and cagA genotype diversity and interferon gamma expression in patients with chronic gastritis and patients with gastric cancer. Rev Gastroenterol Mex 2014;79(4):220-8.

19. Parsonnet J, Friedman GD, Orentreich N, Vogelman H. Risk for gastric cancer in people with CagA positive or CagA negative Helicobacter pylori infection. Gut 1997;40(3):297-301.

20. Azuma T, Ohtani M, Yamazaki Y, Higashi H, Hatakeyama M. Meta-analysis of the relationship between CagA seropositivity and gastric cancer. Gastroenterology 2004;126(7):1926-27; author reply 1927-8.

21. Huang JQ, Zheng GF, Sumanac K, Irvine EJ, Hunt RH. Meta-anal- ysis of the relationship between cagA seropositivity and gastric cancer. Gastroenterology 2003;125(6):1636-44.

22. Sicinschi LA, Correa P, Peek RM, Camargo MC, Piazuelo MB, Romero-Gallo J, Hobbs SS, Krishna U, Delgado A, Mera R, Bravo LE, Schneider BG. CagA C-terminal variations in Helicobacter pylori strains from Colombian patients with gastric precancerous lesions. Clin Microbiol Infect 2010;16(4):369-78

23. Zhang Y, Argent RH, Letley DP, Thomas RJ, Atherton JC. Tyrosine phosphorylation of CagA from Chinese Helicobacter pylori isolates in AGS gastric epithelial cells. J Clin Microbiol 2005;43(2):786-90.

24. Stein M, Bagnoli F, Halenbeck R, Rappuoli R, Fantl WJ, Covacci A. c-Src/Lyn kinases activate Helicobacter pylori CagA through tyrosine phosphorylation of the EPIYA motifs. Mol Microbiol 2002;43(4):97180.

25. Krisch LM, Posselt G, Hammerl P, Wessler S. CagA Phosphorylation in Helicobacter pylori-Infected B Cells Is Mediated by the Nonreceptor Tyrosine Kinases of the Src and Abl Families. Infect Immun 2016;84(9):2671-80.

26. Yong X, Tang B, Li BS, Xie R, Hu CJ, Luo G, Qin Y, Dong H, Yang SM. Helicobacter pylori virulence factor CagA promotes tumorigenesis of gastric cancer via multiple signaling pathways. Cell Commun Signal 2015;13:30. doi: 10.1186/s12964-015-0111-0.

27. Kocazeybek BS, Caliskan R, Erdamar Cetin S, Ergin S, Kuskucu M, Kepil N, Oyku Dinc H, Ziya Erzin Y, Saribas S, Bahar Tokman H, Kalayci F, Akgul O, Yuksel P, Karakullukcu A, Ziver T, Sirekbasan S, Caglar E, Bal K. Patterns of EPIYA motifs among cagA-positive Helicobacter pylori strains: a case-control study in a Turkish population with Eurasian geographical features. J Med Microbiol 2015;64(10):1117-23. 28. Nagase L, Hayashi T, Senda T, Hatakeyama M. Dramatic increase in SHP2 binding activity of Helicobacter pylori Western CagA by EPIYA-C duplication: its implications in gastric carcinogenesis. Sci Rep. 2015; 28;5:15749. doi: 10.1038/srep15749.

29. Liu X, Zheng H, Li X, Wang S, Meyerson HJ, Yang W, Neel BG, Qu CK. Gain-of-function mutations of Ptpn11 (Shp2) cause aberrant mitosis and increase susceptibility to DNA damage-induced malignancies. Proc Natl Acad Sci U S A 2016;113(4):984-9.

30. Hayashi T, Senda M, Suzuki N, Nishikawa H, Ben C, Tang C, Nagase L, Inoue K, Senda T, Hatakeyama M. Differential mechanisms for SHP2 binding and activation are exploited by geographically distinct Helicobacter pylori CagA oncoproteins. Cell reports 2017;20(12):287690 .

31. Lee IO, Kim JH, Choi YJ, Pillinger MH, Kim SY, Blaser MJ, Lee YC. Helicobacter pylori CagA phosphorylation status determines the gp130-activated SHP2/ERK and JAK/STAT signal transduction pathways in gastric epithelial cells. J Biol Chem 2010;285(21):16042-50.

32. Hu ZQ, Ma R, Zhang CM, Li J, Li L, Hu ZT, Gao QI, Li WM. Expression and clinical significance of tyrosine phosphatase SHP2 in thyroid carcinoma. Oncol Lett 2015;10(3):1507-12.

33. Suzuki M, Mimuro H, Suzuki T, Park M, Yamamoto T, Sasakawa C. Interaction of CagA with Crk plays an important role in Helicobacter pylori-induced loss of gastric epithelial cell adhesion. J Exp Med 2005;202(9):1235-47.

34. Watanabe T, Tsuda M, Tanaka S, Ohba Y, Kawaguchi H, Majima T, Sawa H, Minami A. Adaptor protein Crk induces Src-dependent activation of p38 MAPK in regulation of synovial sarcoma cell proliferation. 
Mol Cancer Res 2009;7(9):1582-92.

35. Tsutsumi R, Takahashi A, Azuma T, Higashi H, Hatakeyama $\mathrm{M}$. Focal adhesion kinase is a substrate and downstream effector of SHP-2 complexed with Helicobacter pylori CagA. Mol Cell Biol 2006;26(1):261-76.

36. Chang CC, Kuo WS, Chen YC, Perng CL, Lin HJ, Ou YH. Fragmentation of CagA Reduces Hummingbird Phenotype Induction by Helicobactor pylori. PLoS One 2016;11(3):e0150061.

37. Zhu J. Csk/CD148 and platelet SFK activation: a balancing act! Blood 2018;131(10):1042-3.

38. Huang X, Wang C, Sun J, Luo J, You J, Liao L, Li M. Clinical value of CagA, c-Met, PI3K and Beclin-1 expressed in gastric cancer and their association with prognosis. Oncol Lett 2018;15(1):947-55.

39. Mimuro H, Suzuki T, Tanaka J, Asahi M, Haas R, Sasakawa C. Grb2 is a key mediator of helicobacter pylori CagA protein activities. Mol Cell 2002;10(4):745-55.

40. Yamahashi Y, Hatakeyama M. PAR1b takes the stage in the morphogenetic and motogenetic activity of Helicobacter pylori CagA oncoprotein. Cell Adh Migr 2013;7(1):11-8.

41. Churin Y, Al-Ghoul L, Kepp O, Meyer TF, Birchmeier W, Naumann M. Helicobacter pylori CagA protein targets the c-Met receptor and enhances the motogenic response. J Cell Biol 2003;161(2):249-55.

42. Ye B, Jiang LL, Xu HT, Zhou DW, Li ZS. Expression of PI3K/AKT pathway in gastric cancer and its blockade suppresses tumor growth and metastasis. Int J Immunopathol Pharmacol 2012;25(3):627-36.

43. Murata-Kamiya N, Kurashima Y, Teishikata Y, Yamahashi Y, Saito Y, Higashi H, Aburatani H, Akiyama T, Peek RM, Jr., Azuma T, Hatakeyama M. Helicobacter pylori CagA interacts with E-cadherin and deregulates the beta-catenin signal that promotes intestinal transdifferentiation in gastric epithelial cells. Oncogene 2007;26(32):4617-26.

44. Neal JT, Peterson TS, Kent ML, Guillemin K. H. pylori virulence factor CagA increases intestinal cell proliferation by Wnt pathway activation in a transgenic zebrafish model. Dis Model Mech 2013;6(3):80210.

45. Yong X, Tang B, Xiao YF, Xie R, Qin Y, Luo G, Hu CJ, Dong H, Yang SM. Helicobacter pylori upregulates Nanog and Oct4 via Wnt/ beta-catenin signaling pathway to promote cancer stem cell-like properties in human gastric cancer. Cancer letters 2016;374(2):292-303.

46. Cai C, Zhu X. The Wnt/beta-catenin pathway regulates self-renewal of cancer stem-like cells in human gastric cancer. Mol Med Rep 2012;5(5):1191-6.

47. Kim SY, Lee YC, Kim HK, Blaser MJ. Helicobacter pylori CagA transfection of gastric epithelial cells induces interleukin-8. Cell Microbiol 2006;8(1):97-106.

48. Chen Z, Liu M, Liu X, Huang S, Li L, Song B, Li H, Ren Q, Hu Z, Zhou Y, Qiao L. COX-2 regulates E-cadherin expression through the NF-kappaB/Snail signaling pathway in gastric cancer. Int J Mol Med 2013;32(1):93-100.

49. Snider JL, Allison C, Bellaire BH, Ferrero RL, Cardelli JA. The beta1 integrin activates JNK independent of CagA, and JNK activation is required for Helicobacter pylori CagA+-induced motility of gastric cancer cells. J Biol Chem 2008;283(20):13952-63.

50. Wandler AM, Guillemin K. Transgenic expression of the Helicobacter pylori virulence factor CagA promotes apoptosis or tumorigenesis through JNK activation in Drosophila. PLoS pathogens 2012;8(10):e1002939.

51. Rojanasakul Y. Linking JNK-STAT3-Akt signaling axis to EZH2 phosphorylation: a novel pathway of carcinogenesis. Cell Cycle 2013;12(2):202-3.

52. Lee KS, Kalantzis A, Jackson CB, O’Connor L, Murata-Kamiya N, Hatakeyama M, Judd LM, Giraud AS, Menheniott TR. Helicobacter pylori CagA triggers expression of the bactericidal lectin REG3gamma via gastric STAT3 activation. PLoS One 2012;7(2):e30786.

53. Lima VP, de Lima MA, Andre AR, Ferreira MV, Barros MA, Rabenhorst $\mathrm{SH}$. H pylori (CagA) and Epstein-Barr virus infection in gastric carcinomas: correlation with p53 mutation and c-Myc, Bcl-2 and Bax expression. World J Gastroentero 2008;14(6):884-91.

54. Wei J, Noto JM, Zaika E, Romero-Gallo J, Piazuelo MB, Schneider B, El-Rifai W, Correa P, Peek RM, Zaika AI. Bacterial CagA protein induces degradation of $\mathrm{p} 53$ protein in a $\mathrm{p} 14 \mathrm{ARF}$-dependent manner. Gut 2015;64(7):1040-8.

55. Buti L, Spooner E, Van der Veen AG, Rappuoli R, Covacci A, Ploegh HL. Helicobacter pylori cytotoxin-associated gene A (CagA) subverts the apoptosis-stimulating protein of p53 (ASPP2) tumor suppressor pathway of the host. Proc Natl Acad Sci U S A 2011;108(22):9238-43.

56. Na YJ, Shim KN, Joo YH, Kim SE, Jung HK, Jung SA, Cho MS. RUNX3 methylation, loss of RUNX3 expression and clinicopathologic findings according to Helicobacter pylori $\mathrm{CagA}$ in gastric carcinoma. Korean J Gastroentero 2015;66(2):75-84

57. Tsang YH, Lamb A, Romero-Gallo J, Huang B, Ito K, Peek RM, Jr., Ito Y, Chen LF. Helicobacter pylori CagA targets gastric tumor suppressor RUNX3 for proteasome-mediated degradation. Oncogene 2010;29(41):5643-50.

58. Ivie SE, McClain MS, Torres VJ, Algood HM, Lacy DB, Yang R, Blanke SR, Cover TL. Helicobacter pylori VacA subdomain required for intracellular toxin activity and assembly of functional oligomeric complexes. Infect Immun 2008;76(7):2843-51.

59. Torres VJ, Ivie SE, McClain MS, Cover TL. Functional properties of the p33 and p55 domains of the Helicobacter pylori vacuolating cytotoxin. J Biol Chem 2005;280(22):21107-14.

60. Torres VJ, McClain MS, Cover TL. Interactions between p-33 and p-55 domains of the Helicobacter pylori vacuolating cytotoxin (VacA). J Biol Chem 2004;279(3):2324-31.

61. Leunk RD, Johnson PT, David BC, Kraft WG, Morgan DR. Cytotoxic activity in broth-culture filtrates of Campylobacter pylori. J Med Microbiol 1988;26(2):93-9.

62. Tombola F, Carlesso C, Szabo I, de Bernard M, Reyrat JM, Telford JL, Rappuoli R, Montecucco C, Papini E, Zoratti M. Helicobacter pylori vacuolating toxin forms anion-selective channels in planar lipid bilayers: possible implications for the mechanism of cellular vacuolation. Biophys J 1999;76(3):1401-9.

63. Czajkowsky DM, Iwamoto H, Cover TL, Shao Z. The vacuolating toxin from Helicobacter pylori forms hexameric pores in lipid bilayers at low pH. Proc Natl Acad Sci U S A 1999; 96(5):2001-6.

64. Ricci V, Sommi P, Fiocca R, Necchi V, Romano M, Solcia E. Extracellular $\mathrm{pH}$ modulates Helicobacter pylori-induced vacuolation and VacA toxin internalization in human gastric epithelial cells. Biochem Biophys Res Commun 2002;292(1):167-74

65. Sun J, Wu Y, Su Z, Liu Z, Su B, Liu Z, Liu W, Zhao H, Tana, Ba- 
teer, Eshita Y, Chi B, Zhao L, Fang X, Hao W, Wu S, Bian J, Chen J, Ouyang X. The role of small molecular weight compounds to increase vacuolation induced by VacA toxin in vitro. Toxicol In Vitro 2010;24(5):1373-8

66. Morbiato L, Tombola F, Campello S, Del Giudice G, Rappuoli R, Zoratti M, Papini E. Vacuolation induced by VacA toxin of Helicobacter pylori requires the intracellular accumulation of membrane permeant bases, Cl(-) and water. FEBS Lett 2001;508(3):479-83.

67. Ricci V. Relationship between VacA toxin and host cell autophagy in Helicobacter pylori infection of the human stomach: a few answers, many questions. Toxins (Basel) 2016;8(7).

68. Raju D, Jones NL. Methods to monitor autophagy in H. pylori vacuolating cytotoxin A (VacA)-treated cells. Autophagy 2010;6(1):13843.

69. Jain $P$, Luo ZQ, Blanke SR. Helicobacter pylori vacuolating cytotoxin A (VacA) engages the mitochondrial fission machinery to induce host cell death. Proc Natl Acad Sci U S A 2011;108(38):16032-7.

70. Chatre L, Fernandes J, Michel V, Fiette L, Ave P, Arena G, Jain U, Haas R, Wang TC, Ricchetti M, Touati E. Helicobacter pylori targets mitochondrial import and components of mitochondrial DNA replication machinery through an alternative VacA-dependent and a VacA-independent mechanisms. Scientific reports 2017;7(1):15901.

71. Utsch C, Haas R. VacA's induction of VacA-Containing Vacuoles (VCVs) and their immunomodulatory activities on human $t$ cells. Toxins (Basel) 2016;8(6).

72. Djekic A, Muller A. The Immunomodulator VacA promotes immune tolerance and persistent Helicobacter pylori infection through Its activities on T-cells and antigen-presenting cells. Toxins (Basel) 2016;8(6).

73. D'Elios MM, Montecucco C, de Bernard M. VacA and HP-NAP, Ying and Yang of Helicobacter pylori-associated gastric inflammation. Clin Chim Acta 2007;381(1):32-8.

74. Wang F, Xia P, Wu F, Wang D, Wang W, Ward T, Liu Y, Aikhionbare F, Guo Z, Powell M, Liu B, Bi F, Shaw A, Zhu Z, Elmoselhi A, Fan D, Cover TL, Ding X, Yao X. Helicobacter pylori VacA disrupts apical membrane-cytoskeletal interactions in gastric parietal cells. J Biol Chem 2008;283(39):26714-25.

75. Kobayashi H, Kamiya S, Suzuki T, Kohda K, Muramatsu S, Kurumada T, Ohta U, Miyazawa M, Kimura N, Mutoh N, Shirai T, Takagi A, Harasawa S, Tani N, Miwa T. The effect of Helicobacter pylori on gastric acid secretion by isolated parietal cells from a guinea pig. Association with production of vacuolating toxin by H. pylori. Scand J Gastroenterol 1996;31(5):428-33.

76. Supajatura V, Ushio H, Wada A, Yahiro K, Okumura K, Ogawa H, Hirayama T, Ra C. Cutting edge: VacA, a vacuolating cytotoxin of Helicobacter pylori, directly activates mast cells for migration and production of proinflammatory cytokines. J Immunol 2002;168(6):2603-7. 77. Fujikawa A, Shirasaka D, Yamamoto S, Ota H, Yahiro K, Fukada M, Shintani T, Wada A, Aoyama N, Hirayama T, Fukamachi H, Noda M. Mice deficient in protein tyrosine phosphatase receptor type $\mathrm{Z}$ are resistant to gastric ulcer induction by VacA of Helicobacter pylori. Nat Genet 2003;33(3):375-81.

78. Shirasaka D, Aoyama N, Sakashita M, Kuroda K, Maekawa S, Wambura CM, Miyamoto M, Tamura T, Yahiro K, Wada A, Kurazono H, Hirayama T, Kasuga M. Relationship between gastric ulcer and Helico- bacter pylori VacA detected in gastric juice using bead-ELISA method. Helicobacter 2002;7(5): 281-6.

79. Bridge DR, Merrell DS. Polymorphism in the Helicobacter pylori CagA and VacA toxins and disease. Gut microbes 2013;4(2):101-17.

80. Tsugawa H, Suzuki H, Saya H, Hatakeyama M, Hirayama T, Hirata K, Nagano O, Matsuzaki J, Hibi T. Reactive oxygen species-induced autophagic degradation of Helicobacter pylori CagA is specifically suppressed in cancer stem-like cells. Cell Host Microbe 2012;12(6):76477.

81. Tsugawa H. [Study of infection strategies of Helicobacter pylori and host cell response against CagA oncoprotein]. Nihon Saikingaku Zasshi 2014;69(4):565-75.

82. Montealegre OM, Jaramillo HC, Montealegre LG, Parra GG, Echeverry de PM, Delgado PMP. [Molecular and histological detection of Helicobacter pylori and genotyping based on babA2 and iceA in patients with benign gastric pathologies]. Rev Chilena Infectol 2010; 27(2):112-8

83. Chomvarin C, Namwat W, Chaicumpar K, Mairiang P, Sangchan A, Sripa B, Tor-Udom S, Vilaichone RK. Prevalence of Helicobacter pylori vacA, cagA, cagE, iceA and babA2 genotypes in Thai dyspeptic patients. Int J Infect Dis 2008;12(1):30-6.

84. Podzorski RP, Podzorski DS, Wuerth A, Tolia V. Analysis of the vacA, cagA, cagE, iceA, and babA2 genes in Helicobacter pylori from sixty-one pediatric patients from the Midwestern United States. Diagn Microbiol Infect Dis 2003;46(2):83-8.

85. Gatti LL, Modena JL, Payao SL, Smith Mde A, Fukuhara Y, Modena JL, de Oliveira RB, Brocchi M. Prevalence of Helicobacter pylori cagA, iceA and babA2 alleles in Brazilian patients with upper gastrointestinal diseases. Acta Trop 2006;100(3):232-40.

86. Szczepanik M. Interplay between Helicobacter pylori and the immune system. Clinical implications. J Physiol Pharmacol 2006;57 Suppl 3:15-27.

87. Lee SK, Josenhans C. Helicobacter pylori and the innate immune system. Int J Med Microbiol 2005;295(5):325-34.

88. Sharma SA, Tummuru MK, Blaser MJ, Kerr LD. Activation of IL-8 gene expression by Helicobacter pylori is regulated by transcription factor nuclear factor-kappa B in gastric epithelial cells. J Immunol 1998;160(5):2401-7.

89. Kim Y, Seo JH, Kim H. beta-Carotene and lutein inhibit hydrogen peroxide-induced activation of NF-kappaB and IL-8 expression in gastric epithelial AGS cells. J Nutr Sci Vitaminol (Tokyo) 2011;57(3):21623.

90. Zou J, Shankar N. Roles of TLR/MyD88/MAPK/NF-kappaB signaling pathways in the regulation of phagocytosis and proinflammatory cytokine expression in response to E. faecalis infection. PLoS One 2015;10(8): e0136947.

91. Lamb A, Yang XD, Tsang YH, Li JD, Higashi H, Hatakeyama M, Peek RM, Blanke SR, Chen LF. Helicobacter pylori CagA activates NF-kappaB by targeting TAK1 for TRAF6-mediated Lys 63 ubiquitination. EMBO Rep 2009;10(11):1242-9.

92. Chao X, Zao J, Xiao YG, Li JM, Tao S. Blocking of PI3K/AKT induces apoptosis by its effect on NF-kappaB activity in gastric carcinoma cell line SGC7901. Biomed Pharmacother 2010;64(9):600-4.

93. Jabbour HN, Milne SA, Williams AR, Anderson RA, Boddy SC. Expression of COX-2 and PGE synthase and synthesis of PGE(2)in 
endometrial adenocarcinoma: a possible autocrine/paracrine regulation of neoplastic cell function via EP2/EP4 receptors. Brit J Cancer 2001;85(7):1023-31.

94. Tang M, Wang Y, Han S, Guo S, Xu N, Guo J. Endogenous PGE(2) induces MCP-1 expression via EP4/p38 MAPK signaling in melanoma. Oncol Lett 2013;5(2):645-50.

95. Chaturvedi R, de Sablet T, Peek RM, Wilson KT. Spermine oxidase, a polyamine catabolic enzyme that links Helicobacter pylori CagA and gastric cancer risk. Gut microbes 2012;3(1):48-56.

96. Chaturvedi R, Asim M, Romero-Gallo J, Barry DP, Hoge S, de Sablet T, Delgado AG, Wroblewski LE, Piazuelo MB, Yan F, Israel DA, Casero RA, Jr., Correa P, Gobert AP, Polk DB, Peek RM, Jr., Wilson KT. Spermine oxidase mediates the gastric cancer risk associated with Helicobacter pylori CagA. Gastroenterology 2011;141(5):1696-708 e1691-2.

97. Arancia G, Calcabrini A, Marra M, Crateri P, Artico M, Martone A, Martelli F, Agostinelli E. Mitochondrial alterations induced by serum amine oxidase and spermine on human multidrug resistant tumor cells. Amino Acids 2004;26(3):273-82.

98. Bagchi D, Bhattacharya G, Stohs SJ. Production of reactive oxygen species by gastric cells in association with Helicobacter pylori. Free Radic Res 1996;24(6):439-50

99. Piao JY, Lee HG, Kim SJ, Kim DH, Han HJ, Ngo HK, Park SA, Woo JH, Lee JS, Na HK, Cha YN, Surh YJ. Helicobacter pylori Activates IL-6-STAT3 signaling in human gastric cancer cells: potential roles for reactive oxygen species. Helicobacter 2016;21(5):405-16.

100. Zhou Y, Xia L, Liu Q, Wang H, Lin J, Oyang L, Chen X, Luo X, Tan S, Tian Y, Su M, Wang Y, Chen P, Wu Y, Wang H, Liao Q. Induction of pro-inflammatory response via activated macrophage-mediated NF-kappaB and STAT3 pathways in gastric cancer cells. Cell Physiol Biochem 2018;47(4):1399-410.

101. Hrycay EG, Bandiera SM. Involvement of cytochrome P450 in reactive oxygen species formation and cancer. Adv Pharmacol 2015;74:35-84.

102. Gobert AP, Verriere T, Asim M, Barry DP, Piazuelo MB, de Sablet T, Delgado AG, Bravo LE, Correa P, Peek RM, Jr., Chaturvedi R, Wilson KT. Heme oxygenase-1 dysregulates macrophage polarization and the immune response to Helicobacter pylori. J Immunol 2014;193(6):3013-22.

103. Gobert AP, Asim M, Piazuelo MB, Verriere T, Scull BP, de Sablet T, Glumac A, Lewis ND, Correa P, Peek RM, Jr., Chaturvedi R, Wilson KT. Disruption of nitric oxide signaling by Helicobacter pylori results in enhanced inflammation by inhibition of heme oxygenase-1. J Immunol 2011;187(10):5370-9.

104. Li N, Tang B, Jia YP, Zhu P, Zhuang Y, Fang Y, Li Q, Wang K, Zhang WJ, Guo G, Wang TJ, Feng YJ, Qiao B, Mao XH, Zou QM. Helicobacter pylori CagA protein negatively regulates autophagy and promotes inflammatory response via c-Met-PI3K/Akt-mTOR signaling pathway. Front Cell Infect Mi 2017;7:417.

105. Hisatsune J, Nakayama M, Isomoto H, Kurazono H, Mukaida N, Mukhopadhyay AK, Azuma T, Yamaoka Y, Sap J, Yamasaki E, Yahiro K, Moss J, Hirayama T. Molecular characterization of Helicobacter pylori VacA induction of IL-8 in U937 cells reveals a prominent role for $\mathrm{p} 38 \mathrm{MAPK}$ in activating transcription factor-2, cAMP response element binding protein, and NF-kappaB activation. J Immunol
2008;180(7):5017-27.

106. Iwamoto H, Czajkowsky DM, Cover TL, Szabo G, Shao Z. VacA from Helicobacter pylori: a hexameric chloride channel. FEBS Lett 1999;450(1-2):101-4.

107. Luo JJ, Li CY, Liu S, Yu W, Tang SY, Cai HL, Zhang Y. Overexpression of Helicobacter pylori VacA N-terminal fragment induces proinflammatory cytokine expression and apoptosis in human monocytic cell line through activation of NF-kappaB. Can J Microbiol 2013;59(8):523-33.

108. Tongtawee $T$, Wattanawongdon $W$, Simawaranon $T$, Kaewpitoon S, Kaengpenkae S, Jintabanditwong N, Tangjanyatham P, Ratchapol W, Kangwantas K, Dechsukhum C, Leeanansaksiri W, Kaewpitoon N, Matrakool L, Panpimanmas S. Expression of Cancer Stem Cell Marker CD44 and Its Polymorphisms in Patients with Chronic Gastritis, Precancerous Gastric Lesion, and Gastric Cancer: A Cross-Sectional Multicenter Study in Thailand. BioMed research international 2017;2017:4384823.

109. Lofgren JL, Whary MT, Ge Z, Muthupalani S, Taylor NS, Mobley M, Potter A, Varro A, Eibach D, Suerbaum S, Wang TC, Fox JG. Lack of commensal flora in Helicobacter pylori-infected INS-GAS mice reduces gastritis and delays intraepithelial neoplasia. Gastroenterology 2011;140(1):210-20.

110. Sohn SH, Kim N, Jo HJ, Kim J, Park JH, Nam RH, Seok YJ, Kim YR, Lee DH. Analysis of gastric body microbiota by pyrosequencing: possible role of bacteria other than helicobacter pylori in the gastric carcinogenesis. J Cancer Prev 2017;22(2):115-25.

111. Li J, Perez Perez GI. Is There a role for the non-helicobacter pylori bacteria in the risk of developing gastric cancer? Int J Mol Sci 2018;19(5).

112. Hsieh YY, Tung SY, Pan HY, Yen CW, Xu HW, Lin YJ, Deng YF, Hsu WT, Wu CS, Li C. Increased abundance of clostridium and fusobacterium in gastric microbiota of patients with gastric cancer in taiwan. Sci Rep 2018;8(1):158.

113. Zhou F, Shi J, Fang C, Zou X, Huang Q. Gastric carcinomas in young (Younger than 40 Years) chinese patients: clinicopathology, family history, and postresection survival. Medicine (Baltimore) 2016;95(9): e2873.

114. Jo HJ, Kim J, Kim N, Park JH, Nam RH, Seok YJ, Kim YR, Kim JS, Kim JM, Kim JM, Lee DH, Jung HC. Analysis of gastric microbiota by pyrosequencing: minor role of bacteria other than helicobacter pylori in the gastric carcinogenesis. Helicobacter 2016;21(5):364-74.

115. De Witte C, Schulz C, Smet A, Malfertheiner P, Haesebrouck F. Other Helicobacters and gastric microbiota. Helicobacter 2016;21 Suppl 1:62-8.

116. Dong J, Thrift AP. Alcohol, smoking and risk of oesophago-gastric cancer. Best Pract Res Clin Gastroenterol 2017;31(5):509-17.

117. Ma SH, Jung W, Weiderpass E, Jang J, Hwang Y, Ahn C, Ko KP, Chang SH, Shin HR, Yoo KY, Park SK. Impact of alcohol drinking on gastric cancer development according to Helicobacter pylori infection status. Br J Cancer 2015;113(9):1381-8.

118. Siman JH, Forsgren A, Berglund G, Floren CH. Tobacco smoking increases the risk for gastric adenocarcinoma among Helicobacter pylori-infected individuals. Scand J Gastroenterol 2001; 36(2):208-13.

119. Nishizawa T, Suzuki H, Sakitani K, Yamashita H, Yoshida S, Hata K, Kanazawa T, Fujiwara N, Kanai T, Yahagi N, Toyoshima O. Family 
history is an independent risk factor for the progression of gastric atrophy among patients with Helicobacter pylori infection. United European gastroenterol J 2017;5(1):32-6.

120. Sepulveda A, Peterson LE, Shelton J, Gutierrez O, Graham DY. Histological patterns of gastritis in H. pylori-infected individuals with a family history of gastric cancer. Am J Gastroenterol 2002;97(6):136570.

121. Leung WK, Wong IOL, Cheung KS, Yeung KF, Chan EW, Wong AYS, Chen L, Wong ICK, Graham DY. Effects of Helicobacter pylori treatment on incidence of gastric cancer in older individuals. Gastroenterology. 2018;155(1):67-75.

122. Kim JE, Kim MS, Yoon YS, Chung MJ, Yum DY. Use of selected lactic acid bacteria in the eradication of Helicobacter pylori infection. J Microbiol 2014;52(11):955-62.
123. Lin WH, Lin CK, Sheu SJ, Hwang CF, Ye WT, Hwang WZ, Tsen HY. Antagonistic activity of spent culture supernatants of lactic acid bacteria against Helicobacter pylori growth and infection in human gastric epithelial AGS cells. J Food Sci 2009;74(6):M225-30.

124. Burns M, Amaya A, Bodi C, Ge Z, Bakthavatchalu V, Ennis K, Wang TC, Georgieff M, Fox JG. Helicobacter pylori infection and low dietary iron alter behavior, induce iron deficiency anemia, and modulate hippocampal gene expression in female C57BL/6 mice. PLoS One 2017;12(3):e0173108.

125. Loh JT, Gaddy JA, Algood HM, Gaudieri S, Mallal S, Cover TL. Helicobacter pylori adaptation in vivo in response to a high-salt diet. Infect Immun 2015;83(12):4871-83.

126. Cheung TK, Wong BC. Treatment of Helicobacter pylori and prevention of gastric cancer. J Dig Dis 2008;9(1):8-13. 